\title{
ANALISIS PENGARUH BLENDED LEARNING DAN SERTIFIKASI TERHADAP KOMPETENSI MAHASISWA
}

\author{
Suwarno ${ }^{1}$, Hendi $^{2}$ \\ Universitas Internasional Batam, Jln. Gajah Mada, Sei Ladi, Tiban Indah, Sekupang, Batam, Kepulauan Riau 29442
}

\section{INFORMASI ARTIKEL}

Diterima Redaksi: 5 Agustus 2018

Diterbitkan Online: 30 September 2018

\section{KATA KUNCI}

\begin{tabular}{l}
\hline Blended Learning, Sertifikasi, \\
Kompetensi \\
KORESPONDENSI \\
\hline E-mail: \\
suwarno.liang@uib.ac.id;hendi@uib.ac.id
\end{tabular}

\section{Latar Belakang}

Implementasi Information Communication Technology (ICT) dalam penyelenggaraan pendidikan dapat meningkatkan keunggulan bersaing perguruan tinggi di Indonesia [1], terutama dilihat dari hasil implementasi peningkatan proses pembelajaran dengan $e$ Learning. Hal ini didukung juga oleh penelitian tentang pandangan mahasiswa terhadap LMS (Learning Management System), bahwa

\begin{abstract}
A B S T R A C T
Pembelajaran dengan tambahan e-Learning lebih dikenal dengan nama Blended Learning. Pembelajaran ini dilakukan dengan mengkombinasikan perkuliahan reguler dengan perkuliahan secara online. Pembelajaran Blended Learning di perguruan tinggi, dikombinasikan dengan kebutuhan sertifikasi dari industri sehingga diharapkan dapat menunjang kompetensi mahasiswa. Penelitian ini bertujuan untuk mengetahui tentang analisis pengaruh Blended Learning dan sertifikasi terhadap kompetensi mahasiswa. Target khusus yang ingin dicapai adalah memberikan masukan yang komprehensif terhadap perguruan tinggi mengenai peningkatan kompetensi mahasiswa dengan dukungan metode pembelajaran yang sesuai. Metode yang akan dipakai adalah metode penelitian kuantitatif survei terhadap mahasiswa perguruan tinggi di Provinsi Kepulauan Riau; dibarengi dengan melakukan studi pustaka terhadap Aplikasi Pembelajaran Blended Learning dan sertifikasi dalam hubungannya dengan kompetensi mahasiswa. Manfaat utama dari penelitian ini adalah dapat memberikan kontribusi bagi manajemen perguruan tinggi dalam kaitannya dengan pengembangan sumber daya manusia, khususnya di Kepulauan Riau, sebagai provinsi terluar dari negara Kesatuan Republik Indonesia, agar tercapai kompetensi yang diharapkan. Penelitian ini menghasilkan kesimpulan bahwa Blended Learning dan Sertifikasi secara simultan berpengaruh terhadap variabel Kompetensi.
\end{abstract}

pemanfaatan teknologi informasi di bidang pendidikan menjadi sangat penting [2].

Pembelajaran dengan tambahan $e$ Learning lebih dikenal dengan nama blended lerning, dimana mahasiswa hanya perlu untuk datang ke kampus selama tiga hari, dan sisa dua harinya perkuliahan dilaksanakan secara online learning dalam seminggu perkuliahan [3]. Pembelajaran Blended Learning dilakukan dengan mengkombinasikan perkuliahan reguler dengan perkuliahan secara online; salah satunya 
dengan cara mahasiswa hanya diwajibkan untuk datang ke kampus tiga hari dalam seminggu [4]. Pembelajaran Blended Learning pada perguruan tinggi sudah berhasil dilakukan di Greece [5], walaupun dengan adanya kekhawatiran dari dosen terhadap faktor ketidakhadiran atau tidak ada partisipasi dari mahasiswa dalam pembelajaran ini; walaupun ternyata bahwa Blended Learning menjadi suplemen yang membantu mahasiswa untuk belajar lebih lanjut atau pada saat mereka tidak menghadiri sesi perkuliahan regular [5].

Studi tentang penerapan Blended Learning juga telah dilakukan pada 42 orang dosen di kerajaan Bahrain [6]; dimana dapat disimpulkan bahwa ada perbedaan signifikan pada saat setelah pembelajaran Blended Learning dilaksanakan dan sebelum dilaksanakan yaitu ada peningkatan hasil cognitive skills terutama pada kelompok ekperimen dengan pembelajaran Blended Learning. Studi selanjutnya [7] yang dilakukan pada mahasiswa medical sciences di Universitas Belgrade, dengan membagi responden ke dalam dua bagian; satu kelompok pembelajaran dengan Blended Learning, kelompok lain dilakukan dengan onsite-Learning; menyimpulkan bahwa GPA (Grade Point Average) dan hasil skor tes pengetahuan dari pembelajaran dengan Blended Learning lebih tinggi dibandingkan dengan pembelajaran dengan on-site learning.

Pembelajaran Blended Learning di Amerika Serikat, menurut INACOL [8], telah diikuti oleh 1.2 juta siswa K-12 pada akhir tahun 2010; dengan suplemen pembelajarannya tersedia di 48 dari 50 negara bagian di Amerika Serikat. Di Indonesia sendiri, dari 74 universitas yang disurvei di kota Surakarta, hanya 16 perguruan tinggi atau 21,62\% yang telah mempunyai website $e$-Learning yang menunjang pembelajaran Blended Learning [9].

Isu yang paling penting dalam pembelajaran Blended Learning [10] adalah bagaimana mengimpleentasikan MOOC (Massive Online Open Courses); dimana di Universitas Phoenix, tempat penelitian ini dilakukan, telah memiliki user teregistrasi sebanyak 308.000 pada akhir tahun 2012 pada system ini. Aplikasi Blended Learning untuk MOOC yang dipakai adalah Moodle, sebagai aplikasi yang tersedia open source alias gratis, tak berbayar.

Pembelajaran Blended Learning tersebut tentunya harus terus dievaluasi. Penelitian berikutnya [5] melakukan evaluasi system manajemen pembelajaran untuk Blended Learning di Yunani; dimana platform yang digunakan berdasarkan pada enam dimensi: mahasiswa, dosen, kursus, teknologi, desain system, dan dimensi lingkungan; dan dapat disimpulkan bahwa Open eClass berbasis pada open source Claroline, telah sukses diimplementasikan pada pembelajaran Blended Learning pada Technological Educational Institutions (TEI) di Yunani.

Inisiatif untuk melakukan pembelajaran Blended Learning telah dilakukan juga oleh Microsoft, IBM, Price Waterhouse Coopers, Ashoka, the Center for International Private Enterprise (CIPE) dan El Masry Foundation, dengan membentuk suatu gugus tugas untuk mengembangkan sertifikasi akreditasi tentang pemerintahan anti korupsi untuk NGO (Non Government Organization), dengan cara melakukan pelatihan-pelatihan dengan metode Blended Learning untuk meningkatkan keberhasilan operasional suatu institusi [11]. Hal ini telah juga diteliti oleh Rosemary Ogochukwu Igbo dan Eddiefloyd Maduabuchi Igbo dalam penelitiannya pada tahun 2015 [12], bahwa pengajaran dan modul dapat disampaikan dalam bentuk Blended Learning sebagai metode pembelajaran yang mendukung face to face dan pembelajaran jarak jauh. Mereka juga menyatakan bahwa globalisasi dari pembelajaran jarak jauh telah menciptakan suatu tantangan baru dalam sertifikasi pembelajaran dan akreditasi di perguruan tinggi.

Sertifikasi juga dapat menunjang kompetensi, hal ini telah diteliti juga [13] bahwa program sertifikasi yang telah mengandung teknologi terbarukan dalam pembelajaran, telah meningkatkan kepercayaan pada teknologi dan juga peningkatan pada kompetensi mahasiswa.

Fenomena sertifikasi dan Blended Learning terhadap kompetensi perlu terus diamati. Penelitian mengenai hubungan antara ketiganya telah dilakukan [14], dengan hasil bahwa suatu pendekatan yang ketat untuk melakukan pengajaran Blended Learning dan sertifikasi teknologi pada praktisi pathology adalah sangat penting artinya untuk kemajuan dari pengetahuan dan keterampilan praktisi pathology di Amerika serikat; sehingga meningkatkan kompetensi mereka.

Penelitian pengaruh Blended Learning dan sertifikasi terhadap kompetensi mahasiswa itu 
sendiri belum pernah dilakukan; dan hal ini menjadi suatu masukan bagi peneliti bahwa apakah benar bahwa kompetensi mahasiswa dapat dipengaruhi oleh Blended Learning dan sertifikasi teknologi dilakukan pada saat proses belajarmengajar di perkuliahan pada perguruan tinggi.

Berdasarkan penjabaran diatas maka rumusan masalah adalah Seberapa besar pengaruh Blended Learning dan sertifikasi terhadap kompetensi mahasiswa pada perguruan tinggi di provinsi Kepulauan Riau baik secara pasrsial maupun secara simultan. Tujuan penelitian adalah Untuk mengetahui pengaruh Blended Learning dan sertifikasi terhadap kompetensi mahasiswa pada perguruan tinggi di provinsi Kepulauan Riau baik secara pasrsial maupun secara simultan.

\section{Tinjauan Pustaka}

\section{A. Blended Learning}

Istilah Blended Learning telah digunakan sejak berkembangnya Internet dan World Wide Web pada abad ke-20 ini. Konsep pedagogikal dari Blended Learning adalah strategi yang sukses mengkombinasikan e-Learning dengan face-toface learning dan kolaborasi online [15]. Blended Learning juga didefinisikan sebagai suatu kombinasi dari pengajaran face-to-face dengan computer-mediated instruction [16].

Blended Learning yang digunakan pada penelitian ini mengacu pada definisi dari Norm Friesen [17], bahwa Blended Learning adalah mengacu pada penggunaan dua buah metode yang berbeda, yaitu bisa berbentuk kombinasi blending Classroom Instruction dengan Online Instruction.

\section{B. Sertifikasi}

Sertifikasi adalah mekanisme untuk mempromosikan dan meningkatkan profesi [18], dan sertifikasi juga didefinisikan sebagai suatu ketentuan yang disediakan oleh suatu badan independen dalam bentuk sertifikat yang menyatakan bahwa suatu produk, servis atau system sudah tepat memenuhi kebutuhan spesifiknya [19].

\section{Kompetensi Mahasiswa}

Kompetensi diartikan sebagai suatu keadaan atau kualitas dari pekerjaan seorang individual [20], seseorang dan hasil karyanya dapat dievaluasi sebagai kompeten apabila unjuk http://ejournal.upbatam.ac.id/index.php/cbis kerjanya dapat dikategorikan memuaskan. Penelitian lebih lanjut [21] menyatakan bahwa kompetensi adalah kapabilitas untuk mengaplikasikan atau menggunakan pengetahuan, keterampilan, kemampuan, prilaku, dan karakteristik personal untuk mensukseskan pekerjaan yang kritikal, fungsi spesifik, atau pekerjaan yang diemban. Dalam hal ini, kompetensi mahasiswa diartikan sebagai semua pengetahuan, keterampilan, dan personalitas yang harus dikembangkan dan dikuasai oleh mahasiswa [22].

Berdasarkan teori yang telah diuraikan, peneliti menyimpulkan kerangka berpikir sebagai berikut:

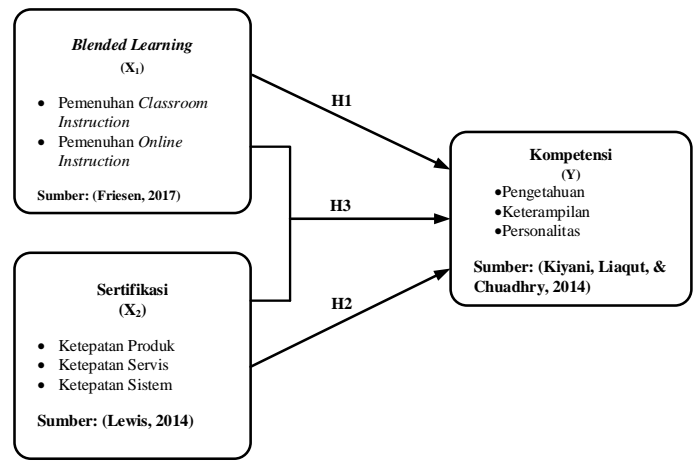

Gambar 1 Kerangka Pemikiran

Dari kerangka berfikir maka Hipotesisnya adalah bahwa Blended Learning dan sertifikasi terhadap kompetensi mahasiswa pada perguruan tinggi di provinsi Kepulauan Riau baik secara Parsial maupun secara Simultan.

\section{Metode Penelitian}

Adapun desain penelitian yang terlebih dahulu ditetapkan di dalam penelitian ini adalah sebagai berikut:

1. Pertama adalah menetapkan judul yang akan diteliti, sehingga dapat diketahui apa yang akan diteliti dan yang menjadi masalah dalam penelitian kuantitatif ini.

2. Merumuskan masalah yang akan diteliti dalam penelitian ini dan perancangan hipotesis.

3. Memilih serta memberi pengukuran variabel. Skala pengukuran dalam penelitian ini menggunakan skala likert.

4. Memilih prosedur dan teknik yang digunakan. Adapun prosedur penelitian yang dilakukan adalah: 
5. Menentukan populasi dan sampel. Dalam penelitian ini populasinya adalah seluruh mahasiswa perguruan tinggi di provinsi Kepulauan Riau dengan jumlah 395 orang. Teknik penarikan sampel yang digunakan adalah Teknik Sampling Aksidental. Teknik penentuan sampel yang digunakan adalah dengan menggunakan Slovin.

6. Teknik pengumpulan data yang digunakan dalam penelitian ini menggunakan kuesioner.

7. Menentukan serangkaian analisis data dan pengujian dengan prosedur statistik. Penelitian ini menggunakan analisis deskriptif dengan menggunakan statistik deskriptif. Pengujian yang digunakan adalah uji kualitas data, uji asumsi klasik, uji pengaruh.

8. Pelaporan hasil penelitian termasuk penelitian dan interprestasi data.

IV. Hasil Dan Luaran Yang Dicapai

A. Analisis dan Hasil Penelitian

\section{Uji Pengaruh}

Uji pengaruh adalah uji untuk memeriksa hubungan antar variabel dependen dengan variabel independen yang dinyatakan dalam bentuk hubungan yang fungsional. Uji pengaruh yang dilakukan adalah sebagai berikut:
a) Uji Regresi Linier Berganda
b) Uji Statistik F
c) Uji t

\section{a). Uji Regresi Linier Berganda}

Hasil dari pemrosesan uji regresi linier berganda dapat ditunjukkan pada tabel 1 berikut ini:

Tabel 1 Hasil Uji Regresi Linear Berganda (Model Summary)

Model Summary

\begin{tabular}{|l|r|r|r|rr|}
\hline Model & \multicolumn{1}{|c|}{ R } & R Square & Adjusted R Square & Std. Error of the Estimate \\
\hline 1 & $.595^{\mathrm{a}}$ & .354 & .351 & .6346 \\
\hline
\end{tabular}

a. Predictors: (Constant), RataRataBL, RataRataSertifikasi

Tabel 2 Hasil Uji Regresi Linear Berganda (ANOVA)

ANOVA $^{\mathrm{a}}$

\begin{tabular}{|ll|r|r|r|r|r|}
\hline Model & & Sum of Squares & df & Mean Square & F & Sig. \\
\hline 1 & Regression & 87.830 & 2 & 43.915 & 109.038 & $.000^{\mathrm{b}}$ \\
& Residual & 160.295 & 398 & .403 & & \\
& Total & 248.125 & 400 & & & \\
\hline
\end{tabular}

a. Dependent Variable: RataRataKompetensi

b. Predictors: (Constant), RataRataBL, RataRataSertifikasi

Tabel 3 Hasil Uji Regresi Linear Berganda (Coefficients)

Coefficients $^{\mathrm{a}}$

\begin{tabular}{|c|c|c|c|c|c|c|c|}
\hline \multirow[b]{2}{*}{ Model } & \multicolumn{2}{|c|}{$\begin{array}{c}\text { Unstandardized } \\
\text { Coefficients }\end{array}$} & \multirow{2}{*}{$\begin{array}{c}\begin{array}{c}\text { Standardized } \\
\text { Coefficients }\end{array} \\
\text { Beta }\end{array}$} & \multirow[b]{2}{*}{$t$} & \multirow[b]{2}{*}{ Sig. } & \multicolumn{2}{|c|}{ Collinearity Statistics } \\
\hline & $\mathrm{B}$ & Std. Error & & & & Tolerance & VIF \\
\hline $1 \quad$ (Constant) & 1.166 & .195 & & 5.966 & .000 & & \\
\hline RataRataSertifikasi & .414 & .047 & .416 & 8.792 & .000 & .725 & 1.379 \\
\hline RataRataBL & .295 & .054 & .260 & 5.494 & .000 & .725 & 1.379 \\
\hline
\end{tabular}

a. Dependent Variable: RataRataKompetensi

Pada tabel diatas dapat dilihat nilai $\mathrm{R}$ Square adalah 0.354 (Model Summary), nilai F http://ejournal.upbatam.ac.id/index.php/cbis adalah 109.038 (ANOVA), nilai Signifikan adalah 0.000 (ANOVA), Nilai B unstandardized 
coefficients, nilai t, dan nilai Signifikannya

(Coefficients). Untuk mudahnya dapat

digambarkan pada tabel 4 berikut:

Tabel 4 Rekap Hasil Analisis Regresi Linear Multiples

\begin{tabular}{|l|c|c|c|}
\hline \multicolumn{1}{|c|}{ Variabel } & Koefisien Regresi & $\begin{array}{c}\text { t } \\
\text { hitung }\end{array}$ & Sig. \\
\hline Konstanta & 1.166 & 5.966 & 0.000 \\
\hline X1 & 0.414 & 8.792 & 0.000 \\
\hline X2 & 0.295 & 5.494 & 0.000 \\
\hline F Hitung = 109.038 & & & \\
\hline $\mathrm{R}^{2}=0.354$ & Sig $=0.000$ & & \\
\hline
\end{tabular}

\section{b). Uji Statistik F}

Berdasarkan hasil dari pemrosesan uji linear berganda, diperoleh nilai F Hitung sebesar 109.038. Langkah yang dilakukan selanjutnya adalah memeriksa nilai $\mathrm{F}$ tabel untuk dibandingkan dengan nilai $\mathrm{F}_{\text {Hitung }}$ yang sudah didapatkan. Perhitungan dari F tabel adalah sebagai berikut:

F-tabel $=(\mathrm{k} ; \mathrm{n}-\mathrm{k})$ dimana $\mathrm{n}$ adalah jumlah sampel penelitian dan $\mathrm{k}$ adalah jumlah variabel independen, sehingga hasilnya adalah $\mathrm{F}$-tabel = $(2 ; 401-2)=(2 ; 399)=3.02$.

Dikarenakan nilai F-hitung (109.038) > nilai Ftabel (3.02) maka dapat disimpulkan bahwa variabel Blended Learning $\left(\mathrm{X}_{1}\right)$ dan variabel Sertifikasi $\left(\mathrm{X}_{2}\right)$ secara simultan berpengaruh terhadap variabel Kompetensi (Y). Pada hasil perhitungan signifikansi sebesar $0.000<0.05$ yang artinya bahwa variabel Blended Learning $\left(\mathrm{X}_{1}\right)$ dan variabel Sertifikasi $\left(\mathrm{X}_{2}\right)$ secara simultan berpengaruh terhadap variabel Kompetensi (Y). Sehingga dapat disimpulkan bahwa hal ini mendukung kesimpulan bahwa variabel independen (Blended Learning dan Sertifikasi) berpengaruh secara simultan terhadap variabel dependen (Kompetensi).

\section{c). Uji t}

Berdasarkan pada hasil dari uji regresi linear berganda yang telah dilakukan, maka hasil analisis untuk uji $\mathrm{t}$ adalah terdapat dua hipotesis yang diajukan yaitu:

1) Hipotesis 1 (H1): Blended Learning $\left(\mathrm{X}_{1}\right)$ berpengaruh signifikan terhadap Kompetensi (Y)

2) Hipotesis 2 (H2): Sertifikasi $\left(\mathrm{X}_{2}\right)$ berpengaruh signifikan terhadap Kompetensi (Y)
Diketahui bahwa nilai koefisien regresi dari Blended Learning $\left(\mathrm{X}_{1}\right)$ adalah positif yaitu 0.414 , sehingga dapat dikatakan bahwa Blended Learning berpengaruh positif terhadap Kompetensi; sehingga semakin meningkat Blended Learning maka akan semakin meningkat pula Kompetensi Mahasiswa.

Selanjutnya untuk mengetahui apakah Blended Learning berpengaruh signifikan atau tidak terhadap Kompetensi, maka nilai koefisien regresi ini akan diuji signifikansinya dengan uji t parsial. berikut:

Hipotesis dalam uji t pertama adalah sebagai

1) $\mathrm{H} 0=$ Blended Learning $\left(\mathrm{X}_{1}\right)$ tidak berpengaruh signifikan terhadap Kompetensi (Y)

2) H1=Blended Learning $\left(\mathrm{X}_{1}\right)$ berpengaruh signifikan terhadap Kompetensi (Y)

Dengan tingkat kepercayaan yang digunakan adalah 95\%, sehingga nilai alpha adalah 0.05 .

Adapun dasar pengambilan keputusan dalam uji t pertama adalah sebagai berikut:

1) H0 diterima dan H1 ditolak apabila nilai thitung $<$ t-tabel atau jika nilai Sig. lebih besar dari 0.05

2) H0 ditolak dan H1 diterima apabila nilai thitung $>$ t-tabel atau jika nilai Sig. lebih kecil dari 0.05 .

Perhitungan selanjutnya adalah menghitung nilai t-tabel yaitu t-tabel $=($ alpha/2;n-k-1) dimana $n$ adalah jumlah responden dan $\mathrm{k}$ adalah jumlah variabel bebas.

Hasil dari nilai t-tabel $=(0.05 / 2 ; 401-2-1)=$ $(0.025 ; 398)$-> pada tabel t dapat dilihat bahwa nilai t-tabel $(0.025 ; 398)$ adalah 2.588 , sehingga dapat disimpulkan sebagai berikut: 
Nilai t-hitung (8.792) > t-tabel $(2.588)=>$ signifikan, dan nilai signifikansi $(0.000)<0.05$ ->signifikan, sehingga kesimpulannya adalah Blended Learning $\left(\mathrm{X}_{1}\right)$ berpengaruh signifikan terhadap Kompetensi (Y).

Selanjutnya untuk mengetahui apakah Sertifikasi berpengaruh signifikan atau tidak terhadap Kompetensi, maka nilai koefisien regresi ini akan diuji signifikansinya dengan uji t parsial. berikut:

Hipotesis dalam uji t pertama adalah sebagai

1) $\mathrm{H} 0=$ Sertifikasi $\left(X_{2}\right)$ tidak berpengaruh signifikan terhadap Kompetensi (Y)

2) H1: Sertifikasi $\left(X_{2}\right)$ berpengaruh signifikan terhadap Kompetensi (Y)

Dengan tingkat kepercayaan yang digunakan adalah 95\%, sehingga nilai alpha adalah 0.05.

Adapun dasar pengambilan keputusan dalam uji t pertama adalah sebagai berikut:

1) H0 diterima dan $\mathrm{H} 1$ ditolak apabila nilai thitung $<\mathrm{t}$-tabel atau jika nilai Sig. lebih besar dari 0.05

2) H0 ditolak dan H1 diterima apabila nilai thitung > t-tabel atau jika nilai Sig. lebih kecil dari 0.05

Perhitungan selanjutnya adalah menghitung nilai t-tabel yaitu t-tabel $=($ alpha/2;n-k-1) dimana $n$ adalah jumlah responden dan $\mathrm{k}$ adalah jumlah variabel bebas.

Hasil dari nilai t-tabel $=(0.05 / 2 ; 401-2-1)=$ $(0.025 ; 398)$-> pada tabel t dapat dilihat bahwa nilai t-tabel $(0.025 ; 398)$ adalah 2.588 , sehingga dapat disimpulkan sebagai berikut:

$\checkmark \quad$ Nilai t-hitung (5.494) $>$ t-tabel (2.588) $=>$ signifikan, dan nilai signifikansi $(0.000)<$ 0.05 ->signifikan, sehingga kesimpulannya adalah Sertifikasi (X2) berpengaruh signifikan terhadap Kompetensi (Y).

\section{Kesimpulan}

Berdasarkan hasil analisis dan pembahasan penelitian, peneliti menyimpulkan hal-hal sebagai berikut:

1. Dikarenakan nilai F-hitung (109.038) > nilai Ftabel (3.02) maka dapat disimpulkan bahwa variabel Blended Learning $\left(\mathrm{X}_{1}\right)$ dan variabel Sertifikasi $\left(\mathrm{X}_{2}\right)$ secara simultan berpengaruh terhadap variabel Kompetensi (Y). Pada hasil perhitungan signifikansi sebesar $0.000<0.05$ http://ejournal.upbatam.ac.id/index.php/cbis yang artinya bahwa variabel Blended Learning $\left(\mathrm{X}_{1}\right)$ dan variabel Sertifikasi $\left(\mathrm{X}_{2}\right)$ secara simultan berpengaruh terhadap variabel Kompetensi (Y). Sehingga dapat disimpulkan bahwa hal ini mendukung kesimpulan bahwa variabel independen (Blended Learning dan Sertifikasi) berpengaruh secara simultan terhadap variabel dependen (Kompetensi).

2. Nilai t-hitung (8.792) $>$ t-tabel (2.588) yang artinya signifikan, dan nilai signifikansi $(0.000)<0.05$ yang artinya signifikan, sehingga kesimpulannya dalah Blended Learning $\left(\mathrm{X}_{1}\right)$ berpengaruh signifikan terhadap Kompetensi (Y).

3. Nilai t-hitung (5.494) > t-tabel (2.588) yang artinya signifikan, dan nilai signifikansi $(0.000)<0.05$ yang artinya signifikan, sehingga kesimpulannya adalah Sertifikasi $\left(\mathrm{X}_{2}\right)$ berpengaruh signifikan terhadap Kompetensi (Y).

\section{Ucapan Terima Kasih}

Penulis mengucapkan terima kasih kepada Ristekdikti, dosen dan mahasiswa yang telah memberi dukungan terhadap penelitian ini.

\section{Daftar Pustaka}

[1] E. Maria, L. S. Wijaya dan C. Fibriani, "Evaluation of Implementation on Information and Communication Technology in Higher Education Institutions in Indonesia Using The IT Balanced Scorecard (Case Study: Satya Wacana Christian University, Salatiga)," Researchers World, pp. 49-57, 2013.

[2] J. J. Siang dan H. B. Santoso, "Students Perspective of Learning Management System," Researchers World, pp. 1-14, 2015.

[3] P. Nicklen, G. Rivers, C. Ooi, D. Ilic, S. Reeves, K. Walsh dan S. Maloney, "An Approach for Calculating Student-Centered Value in Education - A Link between Quality, Efficiency, and the Learning Experience in the Health Professions," PLOS One, pp. 1-11, 2016.

[4] P. Nicklen, G. Rivers, C. Ooi, D. Ilic, S. Reeves, K. Walsh dan S. Maloney, "An 
Approach for Calculating Student-Centered Value in Education - A Link between Quality, Efficiency, and the Learning Experience in the Health Professions," PLOS One, pp. 1-11, 2016.

[5] K. Kabassi, I. Dragonas, A. Ntouzevits, T. Pomonis, G. Papastathopoulos dan Y. Vozaitis, "Evaluating a Learning Management System for Blended Learning in Greek higher Education," SpringerPlus, pp. 1-12, 2016.

[6] M. Al-Doseri, A. Elgazzar dan A. Nouby, “A Strategy For Managing E-Training Environment's Activities And Its Effectiveness In Developing Blended Learning Design Competencies Of Bahraini Secondary Stage Female Teachers," International Journal of Arts \& Sciences, pp. 1-16, 2016.

[7] N. M. Milic, G. Z. Trajkovic1, Z. M. Bukumiric, A. Cirkovic, I. M. Nikolic, J. S. Milin, N. V. Milic, M. D. Savic, A. M. Corac, J. M. Marinkovic dan D. M. Stanisavljevic, "Improving Education in Medical Statistics:Implementing a Blended Learning Model in the Existing Curriculum,” PLOS One, pp. 1-10, 2016.

[8] B. Mohnsen, "Implementing Online Physical Education,” Journal of Physical Education, Recreation \& Dance, pp. 42-47, 2012.

[9] D. Wahyuningsih, Suyanto dan A. Gufron, "Need Assessment of Blended Learning Management in Higher Education in Surakarta, Indonesia," dalam Proceeding The 2nd International Conference On Teacher Training and Education, Surakarta, 2016.

[10] W. B. Bonvillian dan S. R. Singer, "The Online Challenge to Higher Education," Issues in Science and Technology, pp. 2330, 2013.

[11] J. Avina, "The Evolution of Corporate Social Responsibility (CSR) in the Arab Spring," Middle East Journal, pp. 77-92, 2013.

[12] R. O. Igbo dan E. M. Igbo, "Providing Wider Educational Opportunities For Underprevileged Persons Seeking Higher Education Through Distance Education in Africa," International Journal of Arts \& Science, pp. 325-333, 2015.
[13] L. D. Wine, "School Librarians as Technology Leaders an Evolution in Practice," Journal of Education for Library and Information Science, pp. 207-220, 2016.

[14] M. Walter H. Henricks, M. Donald S. Karcher, M. P. James H. Harrison Jr dan M. P. John H. Sinard, "Pathology Informatics Essentials for Residents A Flexible Informatics Curriculum Linked to Accreditation Council for Graduate Medical Education Milestones," Archives of Pathology \& Laboratory Medicine, pp. 113124, 2017.

[15] U. Seeland, A. T. Nauman, A. Cornelis, S. Ludwig, M. Dunkel, G. Kararigas dan V. Regitz-Zagrosek, "eGender-from eLearning to e-Research:a Web-Based Interactive Knowledge-Sharing Platform for Sex-and Gender-Specific Medical Education,” Biology of Sex Differences, pp. 83-103, 2016.

[16] A. Kitchenham, Blended Learning Across Disciplines: Models for Implementation, Portland: Information Science Reference, 2011.

[17] N. Friesen, "Defining_Blended_Learning_NF.pdf," 17 May 2017. [Online]. Available: http://learningspaces.org/papers/Defining Blended_Learning_NF.pdf.

[18] Staff, "Ecology - Restoration Ecology; Study Data from University of Montana Update Knowledge of Restoration Ecology (Professional certification in ecological restoration: improving the practice and the profession)," NewsRx, Atlanta, 2017.

[19] A. M. Lewis, "Technology Certification for Critical Infrastructure Protection,” European Commission, Italy, 2014.

[20] R. Nagarajan dan D. R. Prabhu, "Competence and Capability - A New Look," International Journal of Management, pp. 7-11, 2015.

[21] V. S. Chouhan dan S. Srivastava, "Understanding Competencies and Competency Modelling - A Literature Survey," Journal of Business and Management, pp. 14-22, 2014.

[22] D. A. Kiyani, S. Liaqut dan M. A. Chuadhry, "Impact of Professional Competency of Academia on Academic Achievement of Student at Higher Level," International 
Journal of Technical Research and Applications, pp. 21-27, 2014.

[23] DIKTI, "SERV2 PD DIKTI: Pangkalan Data Pendidikan TInggi," 11 November 2016. [Online]. Available: http://forlap.ristekdikti.go.id/perguruanting gi/homerekap/MUUzMjBFMTEtOTg1Ri00 Qjg3LTk3N0ItQzQ4MkE4NTRCNkQ2/1. [Diakses 11 November 2016].

[24] A. Polymenis, "The Multivariate Central Limit Theorem and its Relationship with Univariate Statistics,” International Journal of Advanced Mathematics and Statistics, pp. 66-67, 2016.

[25] P. Nicklen, G. Rivers, C. Ooi, D. Ilic, S. Reeves4, K. Walsh dan S. Maloney, "An Approach for Calculating Student Centered Value ini Education: A Link between Quality, Efficiency, and the Learning Experience in the Health Professions," PLOS One, pp. 1-11, 2016.

[26] L. Dodson dan D. A. DaSilva, "Enhancing Education Delivery In Guyana at The General Secondary School Level: Opportunities for the Use of ComputerAssisted Instruction," World Journal of Science, Technology and Sustainable Development, pp. 55-67, 2011.

[27] P. Clutterbuck dan O. Seamons, "Enriching Student Engagement And Outcomes Via Online Formative Assesment Within a Virtual Lerning Environment,” International
Journal of Arts \& Sciences, pp. 687-703, 2014.

[28] X. Zhang, “Ana Analysis of Online Students' Behaviors on Course Sites and the Effect on Learning Performance: A Case Study of Four LIS Online classes," Journal of Education for Library and Information Science, pp. 255-270, 2016.

[29] C. Pimiento, "Engaging Students in Paleontology: the Design and Implementation of an Undergraduate-Level Blended Course in Panama," Pimiento Evo Edu Outreach, pp. 1-9, 2015.

[30] H.-W. Tu dan Y.-H. Liu, "Understand The Flipped Classroom: a Reflection,” International Journal of Arts \& Sciences, pp. 249-256, 2016.

[31] S. Maynard dan A. O'Brien, "Scholarly Output: Print and Digital - in Teaching and Research," Journal of Documentation, pp. 384-408, 2010.

[32] L. B. A. Afip, "Motivating Adult Learners Using Blended Learning in Higher Education Institution,” Journal of Arts, Science \& Commerce, pp. 35-42, 2014.

[33] K. Mulqueeny, V. Kostyuk, R. S. Baker dan J. Ocumpaugh, "Incorporating Effective eLearning Principles to Improve Student Engagement in Middle-School Mathematics," International Journal of STEM Education, pp. 2-14, 2015. 